\title{
Justice and Fairness in Negotiation
}

\author{
Daniel Druckman ${ }^{1,2,3} \cdot$ Lynn Wagner $^{4}$
}

\begin{abstract}
In this special issue we display a variety of approaches to the study of justice. Articles from scholars working on questions involving justice and fairness in decision making exchanges calls attention to a variety of research approaches, issue domains, cases and hypotheses used to explore these questions. All of the contributions emphasize analysis, using quantitative and qualitative methods including simulation-experiments, comparative case studies, statistical analyses and game theory. The articles in this collection reveal that justice and fairness concerns extend from the negotiation process to the outcome and into the implementation stage. They share the underlying expectation that individuals and groups gravitate toward fairness and justice in their exchanges with others. Therefore, a full understanding of group decision processes will be incomplete if justice and fairness issues are not considered alongside issues such as power distributions and alternatives to an agreement. The authors also suggest that outcomes built on justice and fairness principles will enhance the efficiency, stability and implementation of the negotiated agreements.
\end{abstract}

Keywords Distributive justice - Fairness - Negotiation process · Pareto-optimal allocations $\cdot$ Procedural justice

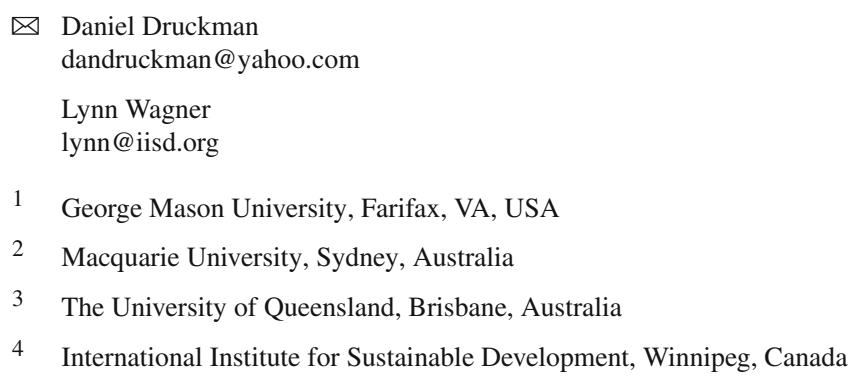




\section{Introduction}

This special issue showcases the many faces of justice in negotiation. Articles from scholars working on questions involving justice and fairness in decision making exchanges expose the reader to a variety of research approaches, issue domains, cases and hypotheses used to explore these questions. Cutting across the contributions is a focus on analysis, using quantitative and qualitative methods including simulationexperiments, comparative case studies, statistical analyses and game theory. Cases addressing issues from security to environmental policy are examined through the lenses of a variety of theoretical perspectives. The articles address the sources, correlates, and contexts within which justice considerations are germane.

As the articles in this collection reveal, justice plays a complex role in group decision making. The articles explore the sources of justice claims, including the more psychological roots and the larger political context. These conceptions of justice are manifested in negotiation processes that involve decisions concerning which groups will be represented in the process, whether they will have access to relevant information and opportunities to speak in order to fully participate in the process, and whether the parties have a choice in accepting the final agreement. The agreement might represent a number of types of justice, from equal distributions of resources under discussion, to splitting the resources according to the parties' inputs or needs, to compensating parties. Assessments of whether the process and outcome were just or fair influence negotiating parties' attitudes toward the agreement, with implications for implementation.

The articles seek to analyze these variables in order to enhance our understanding of how negotiators develop conceptions of justice and how justice considerations influence negotiation processes, outcomes and implementation of agreements. The objective of such an understanding is to enhance future decision making encounters; the final paper explicitly explores how fair (defined as envy-free and Pareto-optimal) allocations could be arrived at. Together, the articles reveal where justice claims come from, the relationship between these claims and outcomes, and the way the claims manifest in a variety of settings including legal negotiations, negotiating peace following civil wars, maritime and territorial disputes, and environmental disputes. These articles are reviewed following an overview of the topic.

\section{The Role of Justice}

In our recent article for the Annual Review of Psychology (Druckman and Wagner 2016), we situate justice in a broad framework of processes of and influences on negotiation. The article highlighted the importance of justice concepts in a variety of negotiations. For example, better agreements were obtained when simulated attorneys representing homeowners and contractors regarded the process as fair (HollanderBlumoff and Tyler 2008) and when national representatives in historical negotiations adhered to principles of procedural justice (Wagner and Druckman 2012). More durable agreements occurred when peace negotiators adhered to equality principles in the outcomes (Albin and Druckman 2012). Further, the implementation of agreements 
are hypothesized to be facilitated when principles related to post-conflict justice, often referred to as transitional justice, guide the post-negotiation period (Binningsbø et al. 2012).

The pre-negotiation period is critical for setting the tone in terms of such relational factors as shared identities and normative considerations that include agreement on procedural issues. By bolstering negotiators' trust and confidence, these factors are likely to increase the chances for a lasting agreement. They also increase a group orientation that emphasizes problem-solving rather than competitiveness (see Lind and Tyler 1988). Interestingly, group-value negotiators also de-emphasize differences in power or use their power advantage to encourage adherence to procedural justice (PJ) principles which often lead to problem solving. A result of these processes is an agreement that embodies the distributive principle of equality. (See Cook and Hegtvedt 1983 for a distinction between the distributive principles of equality and equity.) Equality provisions in agreements bolster the shared identities established during the pre-negotiation stage and pave the way to smooth implementation. The key is to maintain adherence to the principles that guided the process and agreements. For agreements that end violence, this means transitioning from a state of war to peace. For agreements that resolve legal and workplace disputes, this means transitioning from conflictual to cooperative relationships. For both types of agreements, the changes are more likely to last when spoilers are not present during the implementation process (Stedman 2000).

A stage conception of negotiation provides a lens for understanding justice concepts in terms of a linear path: pre-negotiation interactions encourage justice in the process which increases the chances for a stable agreement. An alternative conception views negotiation in terms of a system. This perspective captures bi-directional and cyclical effects of justice variables. It is attuned to the many ways in which justice variables influence and are influenced by the many other factors that operate in a larger negotiating environment. Rather than exploring historical trajectories of justice and relational variables, this approach focuses attention on an interplay among them as they operate together at any point in time. Rather than isolating justice as a focus for analysis, the approach situates justice in a dynamic social environment. Although the Welch article in this collection comes closest to this perspective, there have been few attempts to develop it as a framework for analysis (see Vallacher et al. 2010).

\section{The Many Faces of Justice}

Justice comes in many forms. Although procedural and distributive justice are the primary forms studied by negotiation researchers, other type of justice receive attention as well. A focus on the period of implementation highlights the role played by transitional justice (TJ). Considered usually in the context of civil war, TJ refers to justice during the transition from armed conflict to peace or from an authoritarian to a democratic political system. It may reinforce the justice principles that guided the negotiation process and outcome or veer away from those principles as agreements unfold. Studies on agreement durability address these matters (Albin and Druckman 2012; Wagner and Druckman, this issue). Another form of justice that receives atten- 
tion in the literature is referred to as restorative. This also deals with the post-agreement period and emphasizes ideas of restitution and apology. The large literature on truth and reconciliation commissions focuses primarily on this form of justice (see Hayner 2011) as does the research on acknowledgement and apology (Lewicki et al. 2016).

A fifth form of justice is referred to as retributive, which focuses attention on the actions taken toward a victim and against a harms doer (Darley and Pittman 2003). This form emphasizes the distributive principle of compensation for wrong-doing and is central in the literature on criminal justice. It comes into play as well in discussions of restorative justice, where both negative, as in revenge, and positive, as in restitution, are weighed in decisions. Positive forms of compensation are discussed in the Wagner and Druckman and Albin and Druckman articles in this issue. They are also demonstrated in large-scale trade negotiations by Kapstein (2008). Whether negotiators and mediators are attuned to these distinctions among forms of justice or perceive the concept in holistic ways is an interesting research issue (see Hauenstein et al. 2001; also see the Welch article in this issue for a more holistic conception of justice)

Another distinction refers to the way that justice is studied. The social science literature is divided between normative and descriptive approaches to the topic. The former divides into axiomatic and theoretical or philosophical approaches. Axiomatic studies seek to deduce fair or optimal solutions from stated preferences for alternative outcomes. Arrow (1963) early work on fairness provides a foundation for these studies. The approach is represented by the Brams, Kilgour, and Klamler article in this issue. Theoretical approaches have been inspired primarily by the writings of Rawls (1971). Considered as a work in political philosophy, Rawls offers a theory of society that adheres to the principle of "justice for all." He attempts to reconcile liberty with equality by proposing a well-ordered society in which members cooperate to bring the greatest good for the greatest number of citizens. The prescriptive feature of the approach offers a path in the direction of optimal or integrative negotiating solutions, a goal sought as well by the axiomatic approaches.

Descriptive approaches divide into experimental and case studies. Both seek to discover the way that justice principles impact on decisions made in negotiation and related arenas. Laboratory studies focus on the conditions under which particular justice principles emerge. For example, the debate between equity (Adams 1965) and equality (Deutsch 1985) theorists on when one or the other of these distributive justice (DJ) principles guide decisions has benefitted from experimental findings. Similarly, the debates about procedural justice issues have been enlightened by experimental findings as illuminated by Hollander-Blumoff's article in this issue. Case studies have been more concerned with contexts for negotiation. Justice matters are understood in terms of histories of relationships and types of issues being contested. This is illustrated by the three comparative studies in this issue, where justice is explored in the context of terminating civil wars as well as in attempts to resolve territorial and environmental disputes. The situational and contextual lenses provided by experimental and case study approaches are complementary. Together they contribute to the development of a larger theory of justice. The empirical basis for that theory may also be enriched by developments on the normative front. Rawls' theory of society and the Brams et al algorithms for deducing optimal solutions add insights to those discovered in the laboratory and field. 


\section{Articles in this Issue}

The five articles in this issue offer insights into justice from different perspectives, methodological approaches, and issue areas. Simulation-experiments, statistical analyses of cases, a small number of cases for comparison, and a game-theoretic approach are represented. Justice is studied in the contexts of legal disputes, a sampling of peace agreements, regional territorial conflicts, and cases of environmental negotiations. The key insights from each article are summarized in this section.

In her article on "Procedural Justice Judgments in Legal Negotiations," HollanderBlumoff explores the antecedents of procedural justice judgments in legal negotiation. Earlier PJ research has shown strong effects for PJ on negotiating behavior, and this research is extended by three of the articles in this issue. She attempts to dig deeper into this relationship by identifying what accounts for the finding. She compares four factors thought to influence PJ judgments: voice, courtesy/respect, trust, and neutrality. By including both self-report perceptions and third-party coding of video-taped behaviors, Hollander-Blumoff breaks new ground in this area of research. Few previous studies include behavioral process assessments. Interestingly, she obtains similar results from both types of assessments. Courtesy-respect is found to be the strongest driver of PJ judgments in both the self-report and behavioral data. The importance of courtesy-respect calls attention to the relevance of interpersonal relational rather than more substantive influence of PJ judgments. But it is interesting to note that voice also plays a role in these judgments albeit somewhat less strongly. This finding comports with results from the Albin-Druckman study discussed below. Their analyses of archival documents from negotiations show that fair representation (voice) largely accounts for the relationship between PJ and effectiveness in environmental negotiations.

Hollander-Blumoff's study contributes new insights into how PJ judgments are formed. She asks what specifically accounts for negotiator's perception of a fair process. This approach is used also in the articles by Wagner and Druckman and Albin and Druckman. The former study isolated equality as the key type of DJ accounting for durable agreements and durable peace. As noted above the latter study found that fair representation was the key driver of effectiveness. These findings suggest justice may not be a global concept. Rather it is an aggregate of several parts that may have different effects in negotiation and during the post-negotiation period.

The Hollander-Blumoff study is framed as exploratory. She discusses some limitations and next steps. One limitation is the single dependent variable (DV), which consists of a perception of PJ. Looking forward, her research would benefit from expanding the range of DVs examined including negotiating behavior and outcomes. An example is the earlier Hollander-Blumoff and Tyler (2008) study. A question of interest is: How does courtesy-respect encourage problem-solving behavior and integrative outcomes?

In their article on "Drivers of Durable Peace: The Role of Justice in Negotiating Civil War Termination," Wagner and Druckman develop a multidimensional index of durable peace (DP) following peace agreements. Considered in their research as a dependent variable, the index is used to evaluate the impacts of procedural and distributive justice on reconciliation and changes in societal institutions. Procedural 
justice consists of four parts that surface during the negotiation process: fair play, fair representation, transparency, and voluntary decisions. Distributive justice also consists of four parts that are reflected in the terms of agreement: equality, proportionality, compensation, and need. Their archival analyses of 16 peace agreements negotiated mostly in the 1990s produce a number of interesting findings. The DP index correlates strongly with a measure of the stability of the agreement (SA). More interesting, however, are the mediated effects involving the SA measure: Stable agreements are shown to mediate the relationship between the DJ principle of equality and DP. This variable also mediates the relationship between $\mathrm{PJ}$ and the reconciliation component of DP. Justice variables have a stronger influence on DP when the agreements are stable through time. The impacts on reconciliation and institutions do not include economic growth. That feature of DP is not found to be a dividend of peace agreements.

These authors demonstrate that justice plays an important role in peace following civil wars. Adhering to PJ principles during negotiations and including equality principles in the agreement texts increase the chances for agreements that hold and for societal peace. More broadly, the findings suggest a link between negotiation processes at a micro level of analysis and peace at a macro level. This link highlights the relevance of negotiation to relations between state and non-state actors. It suggests that the way a peace agreement is negotiated has important ramifications for future relations between former combatants and for the institutions in which they participate during the post war period. Building on these findings, Wagner and Druckman have extended their sampling to 50 cases. We await the results from these analyses.

Welch's article on "The Justice Motive in East Asia's Territorial Disputes" underscores the importance of justice concerns in bilateral international disputes. His comparative case analyses show that conflicts can be difficult to resolve even when strategic or economic issues are negligible. Symbolic or ideational conflicts often trigger the justice motive, which can be regarded as an intervening variable between the type of issue at stake (symbolic or economic) and the likelihood of war. He points out that an inflamed sense of justice may be a necessary condition for conflict. This is demonstrated in four of the six cases that he examines. The two exceptions, the Hans Island and Machias Seal Island disputes, are territorial conflicts between countries with a history of cooperation and membership in a shared security community. For these countries, the territorial disputes are not salient political issues and devoid of serious justice claims. Interestingly, none of his cases are disputes spurred by economic or security claims. Although his limited sampling of cases raise issues of generalization to territorial conflicts elsewhere in the world, his analyses provoke important questions about justice for research with larger, more representative samples. These include: What makes justice disputes dangerous?, How might these dangers be reduced?, and What are the prospects of reducing them?

With regard to his first question, Welch calls attention to the relevance of insights from behavioral economics, in particular the concept of reference points. The pain of perceived losses motivate people to persevere in support of a status quo that reinforces maintaining their right to the islands. With regard to his second and third questions, Welch proposes four mechanisms for settling these kinds of disputes: negotiation, persuasion, procedures, and rules. He concludes that the obstacles to settlement by any of these approaches are formidable but not prohibitive. For example, the dispute 
between Japan and South Korea over the Dokdo/Takeshima islands may be amenable to procedural solution. The willingness of China to negotiate a solution to the South China Sea conflicts is not matched by comparable willingness by any of its potential negotiating partners.

The Albin and Druckman article on "Negotiating Effectively" asks whether negotiators who rely on justice principles in the process of bargaining and drafting agreements are more effective than those that are not guided by these principles. The answer is yes depending on the type of negotiation. Focusing on twenty international environmental negotiations divided evenly between bilateral and multilateral cases, the authors analyze relationships between procedural and distributive justice on the one hand and effectiveness on the other. The justice variables are defined in a similar manner as was done in the Wagner and Druckman article in this issue; a difference however is that DJ was coded by Albin and Druckman in the negotiation process rather than the agreement as in Wagner and Druckman. Effectiveness is defined by these authors in terms of the extent of agreement (among parties and on issues), time to reach agreement, and comprehensiveness of the agreement. Their key finding is that adherence to PJ principles predicts effectiveness in the multilateral negotiations. This impact is stronger for the quality of the agreement than for the efficiency of the negotiating process. It is also stronger for fair representation than for the other PJ principles. Adherence to DJ principles during the bilateral negotiating process resulted in a more efficient process (in terms of time to agreement) but not better agreements. Also interesting is the finding that the two types of justice, assessed within the negotiation process, are only weakly related.

The authors' finding of contrasting effects for PJ in the bilateral and multilateral samples may highlight the challenges posed by large-scale conferences of organizing the process and developing trusting relationships in which the delegates appreciate their shared identities. Of particular interest are the roles played by fair representation (voice) and a lack of coercion in producing effective agreements. These aspects of PJ may increase perceptions of trust and shared identities among the delegates more than transparency and fair play. But the findings also have practical implications by identifying areas where multilateral conference organizers can apply their leverage on the process most effectively. Whether these implications apply as well to other multilateral issue areas remains a question to be addressed in further research.

The final article by Brams, Kilgour and Klamler anchors the collection by providing a prescriptive lens on issues of fairness. The authors' game theory approach to determining whether an envy-free allocation exists reveals a condition that "guarantees the existence of a maximin, envy free, and Pareto-optimal allocation." These authors present a procedure for dividing a set of indivisible items that two parties value differently and can rank from best to worst. The procedure is expected to reveal allocations that the parties will view as fair and acceptable, and therefore lead to a constructive settlement of a dispute.

While the real-world disputes examined in the other papers will not necessarily consist of fully identifiable issues that parties can easily rank from best to worst, many of the justice concepts studied in those papers aim to bring the dispute as close to this idealized situation as possible. Ensuring that all parties to the dispute are represented at the table and have access to relevant information - conditions for procedural justice 
- would go a long way toward producing an optimal or integrative solution. Disputing parties, including those with claims of procedural or distributive injustice, would have a full say in assessing the relative value of the issues under discussion and how they are to be divided to satisfy their desire for a fair outcome. While the impartiality that would accompany a strict application of Brams, Kilgour and Klamler's algorithm would not be likely in a real-world application, mediators and parties could benefit by stepping back to consider the requirements of their process, and to ask whether any adjustments could be made to bring more justice to the process and solution options under discussion. Indeed, Welch stresses the necessity of such an assessment when he notes that any settlement of a territorial dispute would require that "claimants would not, on the basis of full information, consider the outcome unjust." Brams, Kilgour and Klamler's algorithm could be used as a standard for evaluating a range of proposed solutions to conflicts.

\section{Conclusion}

The articles in this collection share the underlying expectation that individuals and groups gravitate toward fairness and justice in their exchanges with others. HollanderBlumoff's motivation to explore how individuals form judgments about the fairness of the process is based on research findings that "people care deeply about the fairness of procedures used to resolve their disputes." Welch notes that the negotiation of territorial disputes would require an agreement that would involve "either a division of the stake or compensation adequate to allow one or both parties to convince themselves that relinquishing all or part of a title in return for something else was fair on balance," which he suggests "is easier done in a context of good will and mutual respect." Along these same lines, Albin and Druckman suggest that, given their findings that justice issues influence the direction of the process and the outcome, negotiation analyses need to take justice and related moral/ethical norms into account, rather than focus primarily on interests and power. A full understanding of group decision processes will be incomplete if justice and fairness issues are not considered alongside issues such as power distributions and alternatives to an agreement.

The articles also share the underlying expectation that outcomes built on justice and fairness principles will enhance the stability and implementation of the agreements. The "maximin, envy free, and Pareto-optimal allocation" that could be revealed using the algorithm that Brams, Kilgour and Klamler present would leave the parties with the best joint outcome, which would make them less likely to attempt to return to the table to reallocate the resources at a subsequent time. Wagner and Druckman link the inclusion of justice in the agreement with the stability of peace agreements in the short term as well as the durability of the peace in the long term.

Justice and fairness concerns extend from the negotiation process to the outcome and into the implementation stage. The papers included in this collection reveal that a variety of principles comprise the conceptions of justice and fairness, and vary from stage to stage. Nevertheless, it is possible to characterize and analyze these principles, through studies like those included in this collection, in order to provide 
a fuller understanding of group decision processes, their outcomes, and how likely these outcomes are to be implemented.

Acknowledgements Many thanks are extended to Rebecca Hollander-Blumoff, William Donohue, Serdar Guner, P. Terrence Hopmann, William Maley, Valerie Rosoux, and Dean Tjosvold for serving as reviewers of the papers submitted for publication in this special issue.

\section{References}

Adams JS (1965) Inequity in social exchange. In: Berkowitz L (ed) Advances in experimental social psychology. Academic Press, New York

Albin C, Druckman D (2012) Equality matters: negotiating an end to civil wars. J Confl Resolut 56(2):155182

Arrow KJ (1963) Social choice and individual values, 2nd edn. Yale University Press, New Haven

Binningsbø HM, Loyle CE, Gates S, Elster J (2012) Armed conflict and post-conflict justice, 1946-2006: a dataset. J Peace Res 49(5):731-740

Cook KS, Hegtvedt KA (1983) Distributive justice, equity, and equality. Annu Rev Sociol 9:217-241

Darley JM, Pittman TS (2003) The psychology of compensatory and retributive justice. Personal Soc Psychol Rev 7(4):324-336

Deutsch M (1985) Distributive justice: a social psychological perspective. Yale University Press, New Haven

Druckman D, Wagner L (2016) Justice and negotiation. Annu Rev Psychol 67:387-413

Hauenstein NMA, Mogonicle T, Flinder SW (2001) A meta-analysis of the relationship between procedural justice and distributive justice: implications for justice research. Empl Responsib Rights J 13(1):39-56

Hayner PB (2011) Unspeakable truths: Transitional justice and the challenge of truth commissions, 2nd edn. Routledge, New York

Hollander-Blumoff R, Tyler TR (2008) Procedural justice in negotiation: procedural fairness, outcome acceptance, and integrative potential. Law Soc Inq 33(2):473-500

Kapstein EB (2008) Fairness considerations in world politics: lessons from international trade negotiations. Polit Sci Q 123(2):229-245

Lewicki RJ, Pollin B, Lount RB (2016) An exploration of the structure of effective apologies. Negot Confl Manag Res 9(2):177-196

Lind EA, Tyler TR (1988) The social psychology of procedural justice. Plenum Press, New York

Rawls J (1971) A theory of justice. Harvard University Press, Cambridge

Stedman S (2000) Spoiler problems in peace processes. In: Stern PC, Druckman D (eds) International conflict resolution after the Cold War. National Academy Press, Washington

Wagner L, Druckman D (2012) The role of justice in historical negotiations. Negot Confl Manag Res 5(1):49-71

Vallacher R, Coleman PT, Nowak A, Bui-Wrzosinska L (2010) Rethinking intractable conflict: the perspective of dynamical systems. Am Psychol 65(4):262-278 